\title{
Herbal medicine Guan Chang Fu Fang enhances 5-fluorouracil cytotoxicity and affects drug-associated genes in human colorectal carcinoma cells
}

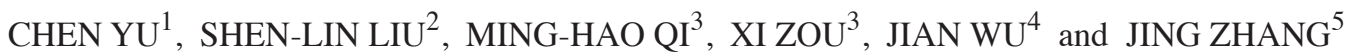 \\ ${ }^{1}$ Department of Integrated Chinese and Western Medicine, The Affiliated Jiangsu Cancer Hospital of \\ Nanjing Medical University and Jiangsu Institute of Cancer Research, Nanjing, Jiangsu 210009; \\ ${ }^{2}$ Senior Expert Consultation Center; ${ }^{3}$ Department of Oncology and ${ }^{4}$ Experimental Center, \\ Affiliated Hospital of Nanjing University of Chinese Medicine, Nanjing, Jiangsu 210029; \\ ${ }^{5}$ Department of Electrocardiology, The Second Affiliated Hospital of \\ Southeast University, Nanjing, Jiangsu 210003, P.R. China
}

Received February 15, 2014; Accepted October 31, 2014

DOI: $10.3892 / \mathrm{ol} .2014 .2766$

\begin{abstract}
Guan Chang Fu Fang (GCFF) is a natural compound, which is extracted from three medicinal plants, Agrimonia pilosa Ledeb., Patrinia scabiosaefolia and Solanum nigrum L. GCFF has demonstrated clinical efficacy in the treatment of colon cancer. At present, 5-fluorouracil (5-FU) is the primary active chemotherapeutic agent used for treating colon cancer. Using median-effect and apoptosis analyses, fluorescence microscopy and western blotting, the present study analyzed the association between GCFF and 5-FU in the human colon adenocarcinoma LoVo cell line. The effect of GCFF on the expression of chemotherapeutic agent-associated genes was also investigated. The results of the synergistic analysis revealed that GCFF exhibited a significant effect upon 5-FU-associated cytotoxicity within the LoVo cell line. This effect was observed over a broad dose-inhibition range (5-95\%), but was particularly significant in the lower concentrations. The flow cytometry results revealed that low doses of GCFF or 5-FU induced S-phase arrest, as did a low-dose combination of the two drugs. After $48 \mathrm{~h}$, GCFF significantly suppressed the expression levels of the chemotherapeutic agent resistance-associated genes within the colon cancer cells. The western blot analysis revealed that the combined effects of 5-FU and GCFF were due to a regulation of the B-cell lymphoma-2 family of proteins. The findings of the
\end{abstract}

Correspondence to: Mr. Jing Zhang, Department of Electrocardiology, The Second Affiliated Hospital of Southeast University, 1-1 Zhong Fu Road, Nanjing, Jiangsu 210003, P.R. China E-mail: zhangjing0425@sina.com

Abbreviations: GCFF, Guan Chang Fu Fang; 5-FU, 5-fluorouracil; OPRT, orotate phosphoribosyl transferase; TS, thymidylate synthase; DPD, dihydropyrimidine dehydrogenase gene; CI, combination index; PI, propidium iodide

Key words: Guan Chang Fu Fang, colon cancer cell, apoptosis, synergy present study suggested that GCFF, when combined with 5-FU, has the potential to be a novel, chemotherapeutic compound for the treatment of colon cancer.

\section{Introduction}

Colorectal carcinoma is one of the most prevalent forms of cancer that exists within Western countries (1), and is the second and third most common type of cancer in males and females, respectively. The majority of patients with advanced colon cancer require cytotoxic chemotherapy as a primary treatment (2). Recently, 5-fluorouracil (5-FU) has been widely used to treat cases of colon cancer. In addition, a number of attempts have been made to improve the objective response rates to chemotherapy, including the use of 5-FU in combination with other agents. However, the optimal combination regimen has not yet been identified, and the standard treatment modality remains debatable (3). Therefore, a requirement exists to identify novel compounds and optimized combined therapies for the treatment of colon cancer. A growing number of patients have selected herbal medicinal compounds as complementary therapies, in combination with conventional chemotherapeutic treatments (4). Due to the narrow therapeutic windows of existing chemotherapeutic drugs, these synergistic or additive interactions may improve the therapeutic results and decrease the necessary doses of current chemotherapeutic agents.

The Chinese herbal formula, Guan Chang Fu Fang (GCFF), contains ingredients from three medicinal plants, Agrimonia pilosa Ledeb., Patrinia scabiosaefolia and Solanum nigrum $\mathrm{L}$. serve as adjuvants to assist the effects of the primary ingredient, A. pilosa. In traditional Chinese medicine, A.pilosa is a plant that possesses anti-cancer (5), anti-oxidant (6), acetylcholinesterase inhibitory (7) and anti-inflammatory (8) activities. Certain studies have identified that A. pilosa contains the phenolic compounds catechin, agrimonin and quercetin (9). However, ethanol extracts of A. pilosa have not yet been examined. P. scabiosaefolia, another component of GCFF, has also been used in Chinese medicinal formulas for the treatment of 
carbuncles, stasis, intestinal abscess and dysmenorrhea (10). Furthermore, P. scabiosaefolia is also an important component of formulated traditional Chinese medicine prescriptions to treat gastrointestinal and breast cancer (11). In addition, a number of in vitro studies have revealed that Solanum nigrum L. has antitumor effects against various types of cancer, including leukemia and stomach, colon and endometrial cancers (12). Further studies indicated that an aqueous extract of Solanum nigrum L. was able to enhance the cytotoxicity of 5-FU, docetaxel, cisplatin and doxorubicin in colorectal cells (13). Due to the variety of adjuvant components, each herbal formula has a different name. The term Guan Chang Fu Fang, meaning 'enema of compound' in Chinese, was derived from the fact that the compound is clinically used for enemas. Our preliminary experiments confirmed that the ethanol extract of GCFF was more effective than the aqueous extract (14), which led to the use of the ethanol extract within the present study. In vitro and in vivo studies have revealed that each component of the GCFF compound has a significant cytotoxic effect upon numerous types of cancer, particularly cancers of the digestive system (12). Despite this, the role of GCFF in the treatment of cancer has not yet been addressed by modern science. Therefore, the present preclinical study aimed to investigate whether the combination of GCFF and 5-FU could produce a significant synergistic interaction, which could treat colon cancer. Furthermore, the expression of chemotherapeutic agent resistance-related genes in colon cancer cells following treatment with GCFF and 5-FU, either alone or in combination, was investigated.

\section{Materials and methods}

Preparation of the GCFF extract. The medicinal plants used for the preparation of the GCFF extract were provided by Bozhou Yonggang Medicinal Herbs Factory Co., Ltd., (Bozhou, China). The preparation included obtaining the ethanol extracts from the crude plant ingredients of A. pilosa, P. scabiosaefolia and Solanum nigrum L., at a ratio of 5:1:1. The plants were homogenized with a Waring blender (Shanghai Specimen Model Factory, Shanghai, China), and then soaked at a 10:1 dilution in double-distilled water for $24 \mathrm{~h}$. The mixture was then heated to $100^{\circ} \mathrm{C}$ for $2 \mathrm{~h}$, after which an 8-fold volume of distilled water was added, followed by further heating for $1.5 \mathrm{~h}$. Next, the residue from the two combined extracts was extracted twice with $80 \%$ ethanol. Firstly, the plant-extract residue was extracted in a 10 -fold volume of ethanol for $2 \mathrm{~h}$, and then an 8 -fold volume of $80 \%$ ethanol was added. The mixture was heated for a further $1.5 \mathrm{~h}$, prior to the merging of the two extracts, and then heated to $70^{\circ} \mathrm{C}$ to evaporate the ethanol. Next, the ethanol extract was concentrated, and the decoction was filtrated. For GCFF, the raw ethanol extract was mixed at a concentration of $1.4 \mathrm{~g}$ herb/ml, and then filtered through a 0.2-mm filter (Microgen, Laguna Hills, CA, USA) prior to use. The quality control of the GCFF preparation, including definition of the correct plants, production origin, implantation, harvesting and processing, was conducted according to the guidelines defined by Nanjing Herb Pharmaceutics, Ltd. The species, plant parts and origins used within the GCFF formula are revealed in Table I. The total weight of the boiled herbs was $210 \mathrm{~g}$.
Cell lines and cell culture. The poorly-differentiated human colon adenocarcinoma LoVo cell line was provided by the Center Laboratory of the Jiangsu Province Chinese Hospital (Nanjing, China). The LoVo cell lines were propagated in RPMI-1640 medium (Gibco-BRL, Carlsbad, CA, USA), which was supplemented with $10 \%$ bovine serum, $100 \mathrm{U} / \mathrm{ml}$ penicillin and $100 \mu \mathrm{g} / \mathrm{ml}$ streptomycinat $37^{\circ} \mathrm{C}$ in a water-saturated atmosphere with $5 \% \mathrm{CO}_{2}$.

Drugs. 5-FU was supplied by the Jiangsu Hengrui Medicine Company (Jiangsu, China). The Cell Titer 96 AQueous One Solution Cell Proliferation Assay kit was purchased from Promega (Madison, WI, USA) and the Annexin V-fluorescein isothiocyanate (FITC) Apoptosis Detection kit was purchased from Invitrogen (Carlsbad, CA, USA).

Cytotoxicity assay and analysis of combination effects. The LoVo tumor cells were grown until the log-phase had been reached, and then were seeded at a density of $8 \times 10^{3}$ cells per well into 96-well plates. The RPMI-1640 medium in each well was replaced with fresh medium, or with medium containing various drug concentrations $(0.21,0.43,0.87,1.75,3.5$ and $7 \mathrm{mg} / \mathrm{ml} \mathrm{GCFF}$, and $0.02,0.04,0.16,0.64,2.5$ and $10 \mu \mathrm{g} / \mathrm{ml}$ $5-\mathrm{Fu}$, as a single drug or in combination), for $48 \mathrm{~h}$. The cells were incubated for an additional $4 \mathrm{~h}$ with MTT, prior to absorbance analysis at $490 \mathrm{~nm}$ using a microplate reader (elx800; Bio-Tek Instruments, Inc., Winooski, VT, USA). The cell growth inhibition rate was calculated using the following formula: Inhibition rate $=1-\mathrm{OD}_{\text {experiment }} / \mathrm{OD}_{\text {control}}$, where OD is the optical density. The dose-response curves were obtained for GCFF: $0.21,0.43,0.88,1.75,3.5$ and $7 \mathrm{mg} / \mathrm{ml}$ and 5-FU: $0.02,0.04,0.16,0.64,2.5$ and $10 \mu \mathrm{g} . \mathrm{ml}$, alone, and for multiple dilutions of fixed-ratio combinations of the two drugs (0.02:0.21, 0.04:0.43, 0.16:0.88, 0.64:1.75, 2.5:3.5 and $10 \mu \mathrm{g} / \mathrm{ml}: 7 \mathrm{mg} / \mathrm{ml}$, 5-FU:GCFF, respectively). The median-effect analysis was performed using the combination index (CI) method, according to Chou and Talalay (15). The CI is defined by the following equation: $\mathrm{CI}=(\mathrm{D})_{1} /(\mathrm{Dx})_{1}+(\mathrm{D})_{2} /(\mathrm{Dx})_{2}+\alpha(\mathrm{D})_{1}(\mathrm{D})_{2} /(\mathrm{Dx})_{1}(\mathrm{Dx})_{2}$. $(\mathrm{Dx})_{1}$ and $(\mathrm{Dx})_{2}$ are the concentrations of $\mathrm{D}_{1}(\mathrm{GCFF})$ and $\mathrm{D}_{2}$ $(5-\mathrm{FU})$ alone, which give $\mathrm{x} \%$ inhibition, whereas $(\mathrm{D})_{1}$ and $(\mathrm{D})_{2}$, as the numerators, are the concentrations of GCFF and 5-FU that produce an identical effect level when in combination. For example, $\alpha=0$ when GCFF and 5-FU are mutually exclusive (with similar modes of action), whereas $\alpha=1$ when GCFF and 5-FU are mutually non-exclusive (with independent modes of action). A CI level of $>1$ indicates antagonism, whereas a CI level of $<1$ indicates synergy and a CI level equal to 1 indicates additivity. The CI ratio represented in the present study was the mean value derived from at least three independent experiments.

Apoptosis assay. The LoVo cells were briefly plated on a $60-\mathrm{mm}$ Petri dish and allowed to grow to reach $75-80 \%$ confluence. The cells were then exposed to GCFF and 5-FU, either alone or in combination, for $48 \mathrm{~h}$. Following incubation, the tumor cells were compared with the untreated control cells. Next, the cells were collected and resuspended in $500 \mu \mathrm{l}$ binding buffer, to which $5 \mu \mathrm{l}$ each of Annexin V-FITC and propidium iodide (PI) was added. The analyses were performed on a flow cytometer (FACScalibur; BD Biosciences, Franklin Lakes, NJ, USA). 
Table I. Guan Chang Fu Fang components.

\begin{tabular}{lccc}
\hline Family & Latin binomial & Plant part & Origin \\
\hline Rosaceae & Agrimonia pilosa Ledeb. & Everything above ground & Hubei, China \\
Valerianaceae & Patrinia scabiosaefolia & Root & Sichuan, China \\
Solanaceae & Solanum nigrum L. & Everything above ground & Anhui, China
\end{tabular}

Cell cycle analysis. In total, $1 \times 10^{5}$ cells were seeded into 6 -well plates and incubated overnight. The cells were then treated with with $0.43 \mathrm{mg} / \mathrm{ml} \mathrm{GCFF}$ and $0.04 \mu \mathrm{g} / \mathrm{ml} \mathrm{5-FU}$, as a single drug or in combination), for $48 \mathrm{~h}$. Next, the cells were harvested, washed with cold phosphate-buffered saline (PBS) and then fixed for $12 \mathrm{~h}$ with $70 \%$ ethanol in PBS at $4^{\circ} \mathrm{C}$. Following incubation, the cells were resuspended in PBS with $100 \mu \mathrm{g} / \mathrm{ml} \mathrm{RNase}$ and $50 \mu \mathrm{g} / \mathrm{ml} \mathrm{PI}$, and incubated at $37^{\circ} \mathrm{C}$ for $30 \mathrm{~min}$. The cell cycle distribution of nuclear DNA was determined by flow cytometry using an FC500 cytometer (Beckman Coulter Inc., Pasadena, CA, USA).

Fluorescence microscopy. In total, $1 \times 10^{6}$ LoVo cells were seeded into 6-well plates, incubated overnight and then treated with either $0.43 \mathrm{mg} / \mathrm{ml} \mathrm{GCFF}, 0.04 \mu \mathrm{g} / \mathrm{ml} 5$-FU or a combination of GCFF and 5-FU for $48 \mathrm{~h}$. The cells were then washed twice with PBS, fixed overnight with cold methanol and acetic acid at a ratio of 3:1, and then stained with $1 \mu \mathrm{g} / \mathrm{ml}$ Hoechst 33342 (Life Technologies, Carlsbad, CA, USA) for $30 \mathrm{~min}$ in the dark. The stained cells were observed using a fluorescence microscope (magnification, x400; IX51; Olympus Corporation, Tokyo, Japan).

Reverse transcription quantitative polymerase chain reaction $(R T-q P C R)$. The total RNA was isolated using TRIzol reagent (Life Technologies), and reverse-transcribed into cDNA using a RT reagent kit (Takara Bio, Inc., Shiga, Japan). The PCR reactions were performed using the ABI 7500 fast real-time PCR system (Life Technologies) and 1X ABsolute QPCR Mix (Thermo Fisher Scientific, Waltham, MA, USA). The sequences of the primers (GenScript USA Inc., Piscataway, NJ, USA) were as follows: Orotate phosphoribosyl transferase (OPRT) forward, 5'-CGAGTAAGCATGAAA CCAGA-3' and reverse, 5'-CTACTCAAATACGCTTCC CCA-3; thymidylate synthase (TS) forward, 5'-ACCTGAATC ACAATCGAGCCA-3' and reverse, 5'-TTGGATGCGGATTGT ACCCT-3'; dihydropyrimidine dehydrogenase (DPD) forward, 5'-TGTTCGGACAGAGCAAGATG-3' and reverse, 5'-CTF CAATCCGGCCATITCTA-3'; and glyceraldehyde 3-phosphate dehydrogenase (GAPDH) forward, 5'-CCATGGAGA AGGCTGGGG-3' and reverse, 5'-CAAAGTTGTCATGGA TGACC-3'. The PCR conditions were $50^{\circ} \mathrm{C}$ for 2 min and $95^{\circ} \mathrm{C}$ for $15 \mathrm{~min}$, followed by 45 cycles at $95^{\circ} \mathrm{C}$ for $15 \mathrm{sec}$ and $60^{\circ} \mathrm{C}$ for $1 \mathrm{~min}$. The relative gene expression quantifications were calculated according to the comparative CT method, using glyceraldehyde 3-phosphate dehydrogenase as an endogenous control and commercial human total RNA (Clontech Laboratories Inc., Mountain View, CA, USA) as a calibrator. The final results were determined according to the $2^{-\Delta \Delta C T}$ method (16).
Table II. $\mathrm{IC}_{50}$ doses of GCFF and 5-FU.

\begin{tabular}{lcc}
\hline \multirow{2}{*}{ Cell line } & \multicolumn{2}{c}{$\mathrm{IC}_{50}($ mean $\pm \mathrm{SD})$} \\
\cline { 2 - 3 } & $\mathrm{GCFF}, \mathrm{mg} / \mathrm{ml}$ & $5-\mathrm{FU}, \mu \mathrm{g} / \mathrm{ml}$ \\
\hline LoVo & $1.62 \pm 0.09$ & $2.91 \pm 0.46$ \\
\hline $\mathrm{IC}_{50}$, half maximal inhibitory concentration; GCFF, Guan Chang Fu \\
Fang; 5-FU, 5-fluorouracil; SD, standard deviation.
\end{tabular}

Western blot analysis. In total, $1 \times 10^{6} \mathrm{LoV}$ cells were seeded into 6-well plates, and incubated overnight. The cells were treated according to the aforementioned instructions. Next, the cells were washed twice with ice-cold PBS. The total proteins were solubilized and extracted using a lysis buffer, which consisted of 20 mM HEPES (pH 7.9), 20\% glycerol, $200 \mathrm{mM} \mathrm{KCl,} 0.5 \mathrm{mM}$ EDTA, $0.5 \%$ NP40, $0.5 \mathrm{mM}$ DTT and $1 \%$ protease inhibitor cocktail. The protein concentrations were determined using a bicinchoninic acid protein assay. The samples were separated using SDS-PAGE, and then transferred to polyvinylidene fluoride membranes by electroblotting, prior to antibody probing with rabbit anti-human B-cell lymphoma-2 (Bcl-2)-associated X protein (Bax) polyclonal antibody $(1: 1,000$; Cell Signaling Technology, Inc., Danvers, MA, USA), rabbit anti-human Bcl-2 polyclonal antibody (1:1,000; Santa Cruz Biotechnology, Inc., Santa Cruz, CA, USA) and rabbit anti-human Bcl-2 19-kDa interacting protein 3 (Bnip3) polyclonal antibody $(1: 1,000$; Santa Cruz). The membranes were then incubated with goat anti-rabbit IgG-horseradish peroxidase secondary antibodies (dilution, 1:10,000; Cell Signaling Technology, Inc.). The blots were developed with an enhanced chemiluminescence kit, and each western blot assay was repeated three times.

Statistical analysis. The values are expressed as the mean \pm standard deviation. The statistical comparisons were performed using Student's t-test. $\mathrm{P}<0.05$ was used to indicate a statistically significant difference.

\section{Results}

Cytotoxicities of GCFF and 5-FU against LoVo cells. The cytotoxic activities of GCFF and 5-FU were investigated individually. As expected, GCFF and 5-FU individually inhibited the proliferation of the LoVo cells in a dose-dependent manner. Table II reveals the half maximal inhibitory concentration $\left(\mathrm{IC}_{50}\right)$ doses for the LoVo cells upon exposure to GCFF or 5-FU. The response of the LoVo cells to the different drugs were significantly different $(\mathrm{P}=0.003)$. 
A

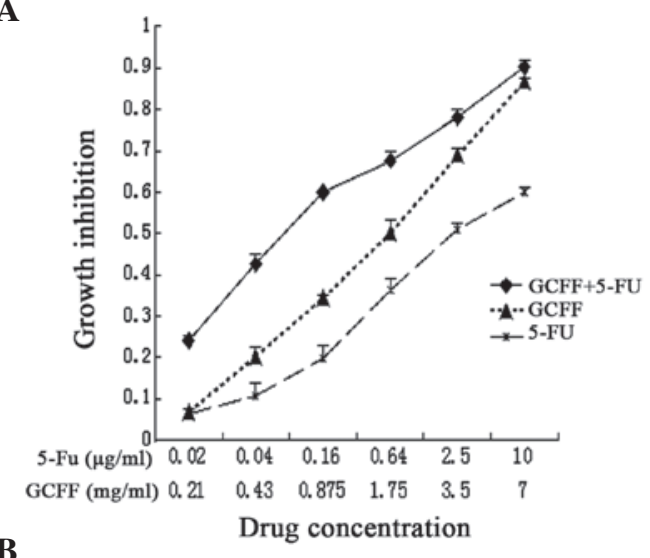

B

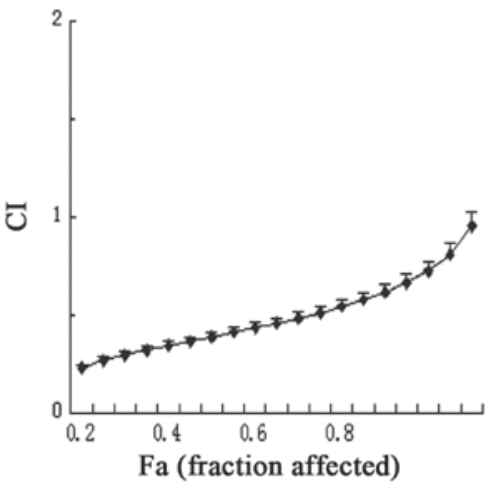

C

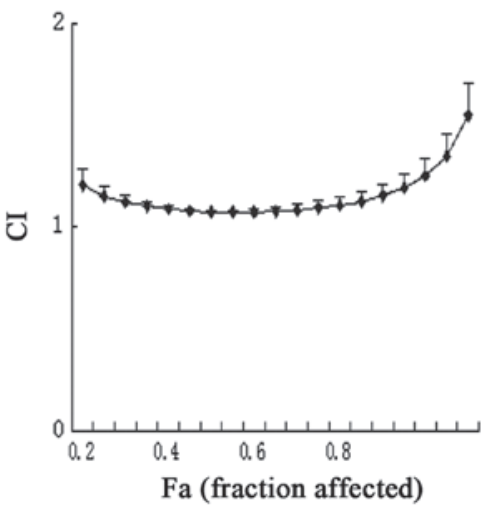

Figure 1. (A) Dose-response curves of the human colon adenocarcinoma LoVo cells treated with Guan Chang Fu Fang (GCFF) and 5-fluorouracil (5-FU), alone or in combination. (B) Combination index (CI) values of the LoVo cells at different levels of growth inhibition (as represented by the fraction affected) induced by GCFF plus 5-FU. (C) CI values according to the treatment schedule of LoVo cells with the chemotherapeutic agents, with administration of 5-FU preceding that of GCFF. The cells were pretreated with 5-FU for $24 \mathrm{~h}$, followed by the administration of GCFF at fixed ratios for $48 \mathrm{~h}$. The data points indicate the means of at least three independent experiments, and the bars indicate the standard deviations. $\mathrm{Cl}<1,=1$ and $>1$ indicate synergism, addition and antagonism, respectively.

Median-effect analysis of combined GCFF and 5-FU in vitro. Fig. 1A presents the dose-response curves for the LoVo cells that were exposed to GCFF and 5-FU, alone or in combination. The combination of GCFF and 5-FU demonstrated significant proliferative inhibition of the LoVo cells at the majority of doses $(0.21-3.5 \mathrm{mg} / \mathrm{ml} \mathrm{GCFF})(\mathrm{P}=0.008)$. Fig. 1B reveals the cytotoxic effect upon the cells simultaneously treated with GCFF and 5-FU. As the CI values were
A
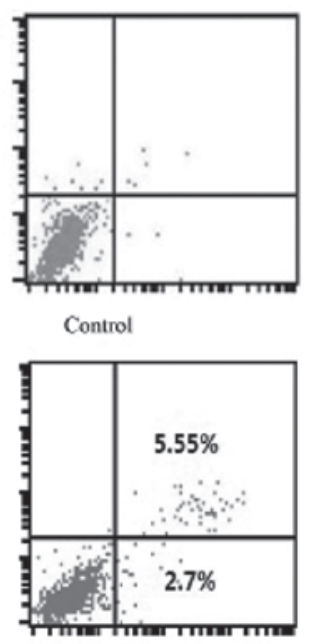

0. $04 \mu \mathrm{g} / \mathrm{ml} 5$ - FU

$\mathbf{B}$

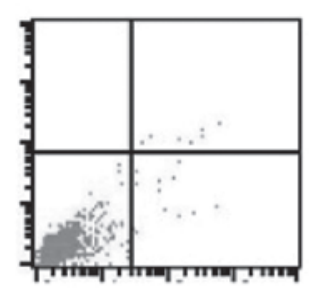

Control

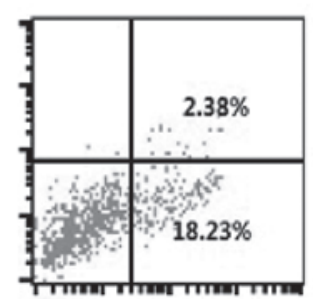

$0.16 \mu \mathrm{g} / \mathrm{ml} \quad 5-\mathrm{Fl}$

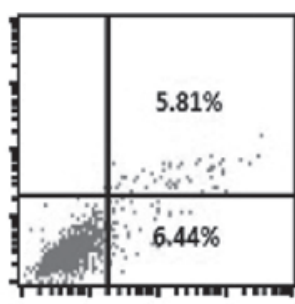

$0.43 \mathrm{mg} / \mathrm{ml} \mathrm{GCFF}$

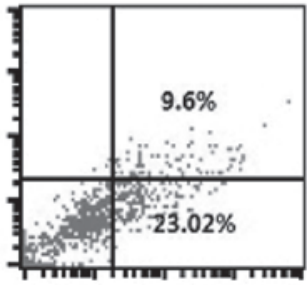

$0.43 \mathrm{mg} / \mathrm{ml} \mathrm{GCFF}+0.04 \mu \mathrm{g} / \mathrm{ml} 5-\mathrm{Fu}$

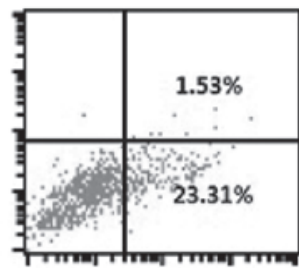

$0.88 \mathrm{mg} / \mathrm{ml}$ GCFF

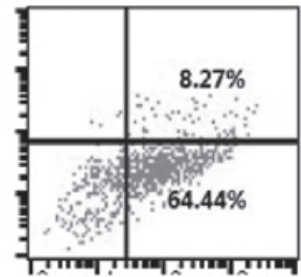

$0.88 \mathrm{mg} / \mathrm{ml} \mathrm{GCFF}+0.16 \mu \mathrm{g} / \mathrm{m} 15-\mathrm{Fu}$

Figure 2. Annexin V-fluorescein isothiocyanate and propidium iodide double-staining to analyze the apoptotic status of the treated human colon adenocarcinoma LoVo cell line. (A) Low-dose drug and (B) moderate-dose drug. GCFF, Guan Chang Fu Fang; 5-FU, 5-fluorouracil.

below a relatively broad range of killed cell fractions, this suggested that GCFF exhibited a synergistic effect upon the cytotoxicity of 5-FU over a broad dose-inhibition range. In addition, the present study analyzed the effect of sequential drug delivery upon the LoVo cells; GCFF or 5-FU were administered alone for $24 \mathrm{~h}$, prior to administration of the second drug. The treatment schedule in which GCFF was administered prior to 5-FU demonstrated a synergistic growth inhibitory effect, similar to that observed in the simultaneous treatment regimen. However, significant antagonistic effects were identified when the cells were treated in the reverse order ( $\mathrm{P}=0.01$; Fig. 1C). These results indicated that the simultaneous treatment and administration of GCFF prior to 5-FU was more effective compared with the reverse order.

Apoptotic effects mediated by GCFF and 5-FU. The Annexin V-FITC and PI double-staining was performed in order to distinguish between the apoptotic cells and the 
Table III. Percentage of cells in each phase of the cell cycle, and total percentage of apoptotic cells, following $48 \mathrm{~h}$ of incubation.

\begin{tabular}{lcc}
\hline Drug (concentration) & Cell cycle phase $(\%$ of cells $)$ & \% of apoptotic cells \\
\hline Control & $\mathrm{G}_{0} / \mathrm{G}_{1}(71.45)$ & $\mathrm{S}(25.76)$ \\
& $\mathrm{G}_{2} / \mathrm{M}(2.79)$ \\
GCFF $(0.43 \mathrm{mg} / \mathrm{ml})$ & $\mathrm{G}_{0} / \mathrm{G}_{1}(67.81)$ \\
& $\mathrm{S}(27.99)$ \\
5 -FU $(0.04 \mu \mathrm{g} / \mathrm{ml})$ & $\mathrm{G}_{2}(4.25)$ \\
& $\mathrm{G}_{0} / \mathrm{G}_{1}(67.33)$ \\
$\mathrm{S}(30.08)$ & $\mathrm{G}_{2} / \mathrm{M}(2.59)$ \\
$\mathrm{GCFF}(0.43 \mathrm{mg} / \mathrm{ml})+5-\mathrm{FU}(0.04 \mu \mathrm{g} / \mathrm{ml})$ & $\mathrm{G}_{0} / \mathrm{G}_{1}(60.98)$ \\
& $\mathrm{S}(38.06)$ \\
& $\mathrm{G}_{2} / \mathrm{M}(0.97)$ \\
\hline
\end{tabular}

GCFF, Guan Chang Fu Fang; 5-FU, 5-fluorouracil.
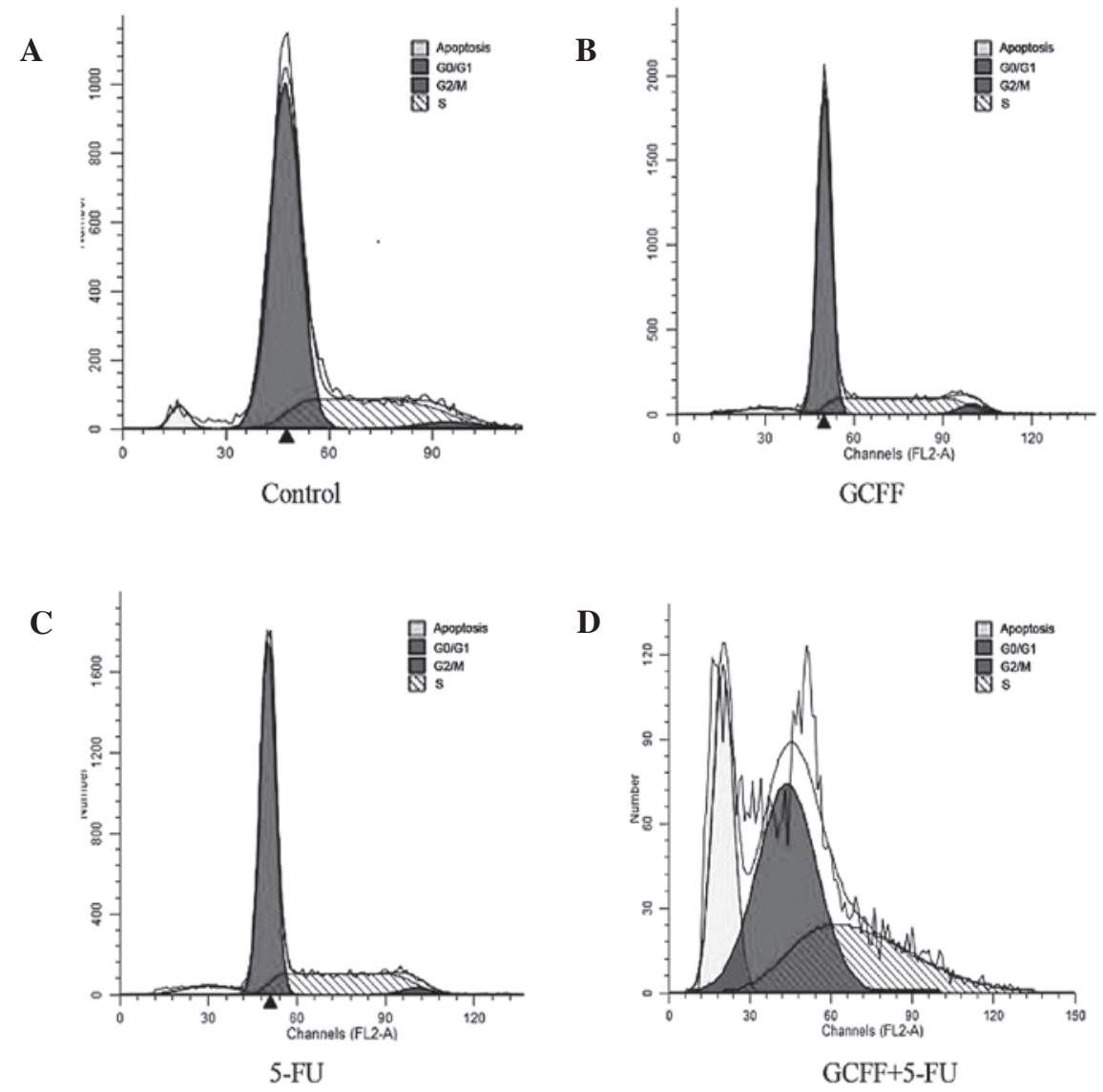

Figure 3. Cell cycle arrest in human colon adenocarcinoma LoVo cells following $48 \mathrm{~h}$ of treatment. (A) Untreated control; (B) Guan Chang Fu Fang (GCFF); (C) 5-fluoroucil (5-FU) and (D) GCFF+5-FU.

other cell populations. The LoVo cell lines were treated with GCFF and 5-FU, alone and in combination. The percentage of apoptotic cells present following treatment with 5-FU was significantly increased by the co-administration of GCFF $(\mathrm{P}=0.003)$. This indicated that the simultaneous treatment of GCFF and 5-FU induced apoptosis in a synergistic manner (Fig. 2). In particular, the percentages of LoVo cells that had undergone early apoptosis, induced by single-agent treatment with either GCFF and 5-FU, were 23.31 and $18.23 \%$, respectively, whereas the percentage of apoptotic cells following the combined drug regimen increased to $64.44 \%$. 
A

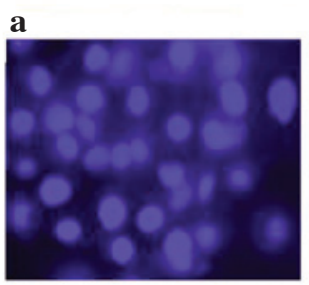

B

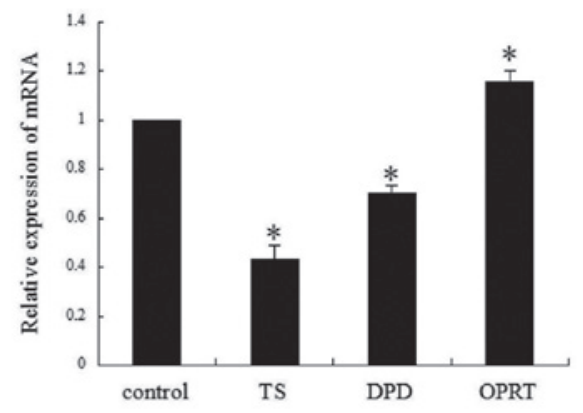

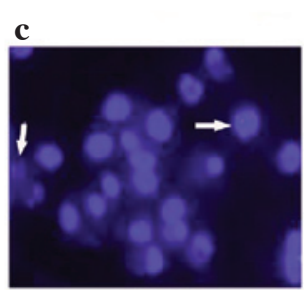
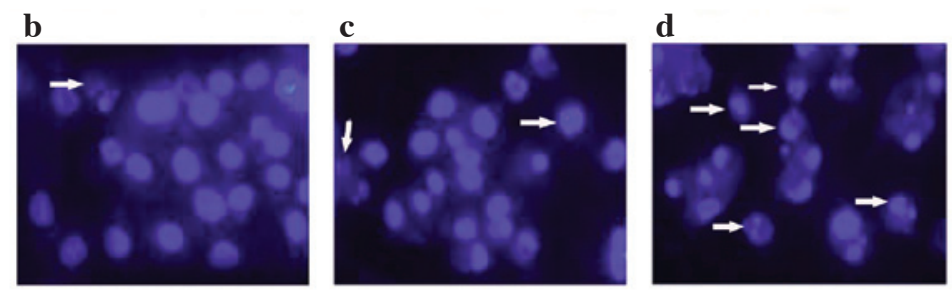

C

Control

GCFF

5-FU GCFF+5-FU

Bcl-2

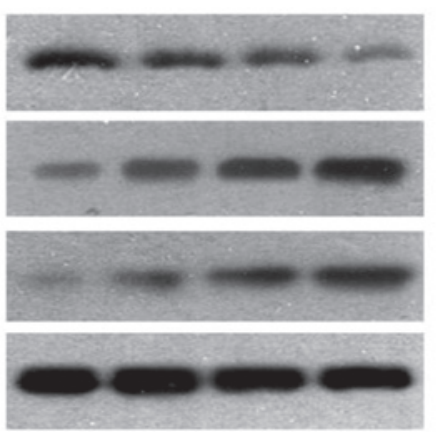

Figure 4. (A) Hoechst 33342 staining revealing the presence of apoptotic cells. The human colon adenocarcinoma LoVo cells were (a) left untreated or treated for $48 \mathrm{~h}$ with either (b) $0.43 \mathrm{mg} / \mathrm{ml}$ Guan Chang Fu Fang (GCFF), (c) $0.04 \mu \mathrm{g} / \mathrm{ml}$ 5-fluoroucil (5-FU) or (d) GCFF + 5-FU. Compared with the control group, the GCFF- and 5-FU-treated cells exhibited chromatin condensation, nuclear fragmentation and apoptotic bodies (white arrows). (B) GCFF suppressed the mRNA expression of certain chemotherapeutic agent resistance-related genes (TS, DPD and OPRT) in the LoVo cells. The changes in the relative gene expression levels following a 48-h treatment with the half maximal inhibitory concentration of GCFF are revealed ("P<0.05 vs. the control). (C) Western blot analysis revealing the combined effects of GCFF and 5-FU upon the expression of members of the B-cell lymphona-2 (Bcl-2) family of proteins. LoVo cells were treated with $0.43 \mathrm{mg} / \mathrm{ml} \mathrm{GCFF}, 0.04 \mu \mathrm{g} / \mathrm{ml}$ 5-FU or GCFF + 5-FU for $48 \mathrm{~h}$. $\beta$-actin served as the control. Bnip3, Bcl-2 19-kDa interacting protein 3; Bax, Bcl-2-associated X protein; TS, thymidylate synthase; DPD, dihydropyrimidine dehydrogenase; OPRT, orotate phosphoribosyl transferase.

GCFF induces $S$-phase cell cycle arrest in LoVo cells. Due to the significant effect of the GCFF and 5-FU co-administration upon the apoptotic rate of the LoVo cells, the present study also examined the potential effects of the combined GCFF and 5-FU regimen upon the cell cycle distribution of LoVo cells at doses below $\mathrm{IC}_{30}$. As revealed in Fig. 3 and Table III, the LoVo cells treated with $0.43 \mathrm{mg} / \mathrm{ml} \mathrm{GCFF}$ and $0.04 \mu \mathrm{g} / \mathrm{ml}$ 5 -FU demonstrated a larger number of cells in the S-phase $(38.06 \pm 1.90 \%)$ compared with the cells treated with GCFF alone $(27.99 \pm 0.38 \%)$. Furthermore, at lower doses, treatment with GCFF increased the number of cells in the S-phase of the cell cycle. Therefore, the results of the present study suggested that following a 48-h treatment with a low-dose combination of the two drugs, the cells were arrested in the S-phase of the cell cycle.

Percentage of apoptotic cells induced by combination therapy is significantly higher compared with monotherapy. Following a 48 -h incubation with either $0.43 \mathrm{mg} / \mathrm{ml} \mathrm{GCFF}, 0.04 \mu \mathrm{g} / \mathrm{ml}$ 5 -FU or a combination of the two, the cells were examined by fluorescence microscopy. The chromatin condensation, nuclear fragmentation and apoptotic bodies were clearly identified in the treated cells (Fig. 4A). Compared with the monotherapy-treated cells, the percentage of apoptotic cells increased significantly following treatment with the combined therapy $(\mathrm{P}=0.005)$.

GCFF affects the mRNA expression of chemotherapeutic agent resistance-related genes. To explain the mechanisms that underlie the synergistic association between GCFF and
5-FU, the present study hypothesized that GCFF may affect the expression of certain chemotherapeutic agent resistance-related genes, namely OPRT, TS and DPD, which could effect the sensitivity of the LoVo cells to 5-FU. The cells were incubated for $48 \mathrm{~h}$ with GCFF or 5-FU alone, at their respective $\mathrm{IC}_{40}$ values, or in combination. As revealed in Fig. $4 \mathrm{~B}$, the expression levels of TS and DPD were significantly downregulated following treatment with GCFF alone. By contrast, the expression levels of OPRT were significantly upregulated by GCFF. However, administration of 5-FU alone did not downregulate the expression of the drug resistance-associated genes.

Combined effect of GCFF and 5-FU on the expression of the Bcl-2 family of proteins. In order to investigate the molecular mechanisms that underlie the combined anticancer effects of GCFF and 5-FU, the effects of GCFF and 5-FU, alone or in combination, upon the expression of the Bax, Bcl-2 and Bnip3 were investigated. As shown in Fig. 4C, the western blot analysis demonstrated that treatment with either GCFF or 5-FU alone reduced Bcl-2 expression, and increased Bax and Bnip3 expression. Furthermore, the combined GCFF and 5-FU treatment significantly reduced $\mathrm{Bcl}-2$ expression, and increased Bax and Bnip3 expression.

\section{Discussion}

The use of active combination chemotherapy has the potential to reduce drug toxicity and dosages, and address the issue of drug resistance. The aim of the present study was 
to investigate whether the cytotoxic effect of 5-FU could be enhanced by the Chinese herbal medicinal compound, GCFF; this was determined using media-effect analysis, flow cytometry and fluorescence microscopy. The results of the present study indicated that the simultaneous administration of GCFF and 5-FU inhibited cell growth and induced apoptosis in a synergistic manner within the LoVo cell line. It was concluded that GCFF contributed to 5-FU-induced apoptosis and growth inhibition. Next, low doses of GCFF and 5-FU were revealed to induce S-phase cell cycle arrest within the LoVo cells via the Bcl-2 family of proteins. Finally, the expression levels of certain chemotherapeutic agent resistance-related genes were identified to be downregulated by GCFF alone and in combination with 5-FU. Overall, the results indicated that GCFF may be a potential candidate for a combined therapy approach alongside 5-FU. The underlying therapeutic mechanisms of this combined therapy may be attributable to a downregulation of certain chemotherapeutic agent resistance-related genes and a synergistic effect upon the rate of cellular apoptosis. Complementary and alternative medicines have been increasingly accepted by patients with cancer in China (6), and a number of patients have taken herbal medicines prior to or during chemotherapy. One previous study revealed that certain herbal medicinal formulae improve the clinical outcomes of chemotherapy (17). However, the potential underlying mechanisms have not yet been identified. Another prior study demonstrated the potential of a number of plant-derived compounds to sensitize tumor cells to chemotherapeutic agents and restore the sensitivity of certain drug-resistant cells (16). However, further elucidation was required as to whether the herbal medicinal formulae could sensitize tumor cells to chemotherapeutic agents. In the present study, a media-effect analysis was performed in order to observe the interaction between GCFF and 5-FU in the LoVo cell lines. In the future, similar studies could be performed upon other cell lines to further investigate the therapeutic potential of combination regimens against different types of tumor cells.

In recent years, 5-FU has been widely administered for the treatment of colon cancer (18). 5-FU is able to induce DNA damage, either directly or indirectly (19), and initiate apoptosis via the p53-dependent pathway (20). A number of experimental studies have revealed that the overexpression of chemotherapy agent resistance-related genes is associated with drug resistance. The DNA synthase enzyme, TS, is targeted by $5-\mathrm{FU}$ and possesses an important role in the efficacy of 5-FU. High levels of TS expression have been demonstrated to contribute to the occurrence of 5-FU resistance and poor clinical outcomes (21). Certain in vivo and in vitro studies have revealed that OPRT is one of the key enzymes involved in 5-FU metabolism, and that phosphorylation of its active metabolite is necessary to inhibit cellular DNA synthesis and induce RNA dysfunction (22). In addition, OPRT mRNA expression has been demonstrated to predict 5-FU sensitivity; specifically, patients with high OPRT expression are more sensitive to 5-FU treatment, and are therefore more likely to benefit from it (23). DPD is an enzyme that catalyzes the major catabolic step during pyrimidine metabolism (24). A previous study identified that low levels of DPD were associated with low TS expression, and were also correlated with responses to 5-FU-based chemotherapy (25). Further studies have revealed that, in addition to being an important determinant of 5-FU pharmacokinetics and clinical toxicity, DPD activity is also a significant factor involved in the determination of 5-FU availability for the production of active metabolites within tumors (26). This finding highlights the potential of DPD activity to predict the response of tumors to 5-FU therapy. In the present study, TS and DPD mRNA were revealed to be significantly downregulated by GCFF, alone or in combination with 5-FU. By contrast, treatment with 5-FU alone did not downregulate the expression of the resistance-associated genes. This finding may explain why GCFF was able to sensitize the cells to 5-FU, and why the synergistic effect of the simultaneous treatment regimen and the administration of GCFF prior to 5-FU, differed from the effect observed upon the administration of 5-FU prior to GCFF.

The Bcl-2 family of proteins are key regulators of the apoptotic pathway (19). The results of the present study revealed that treatment of the LoVo cells with GCFF, in combination with 5-FU, significantly decreased the expression of Bcl-2, but increased the expression of Bax and Bnip3. This finding indicated that GCFF and 5-FU induce apoptosis by regulating the expression of the Bcl-2 family of proteins. The mitochondrial protein Bnip3, formerly known as NIP3, is a member of the Bcl-2 family that induces apoptosis via the mitochondrial permeability transition pore in the absence of a functional $\mathrm{BH} 3$ domain. In normal tissues, endogenous Bnip3 is loosely associated with the mitochondrial membranes, but during the induction of apoptosis, it is fully integrated within the outer mitochondrial membrane, with the $\mathrm{N}$-terminus remaining in the cytoplasm and the C-terminus in the membrane (27). The Bcl-2 proteins, in particular Bnip3, mediate the balance between pro- and anti-apoptotic actions. This balance has a significant role in tumor evolution processes. Further analysis, through the examination of gene expression profiles of these different pathways, is required.

\section{References}

1. Ferlay J, Autier P, Boniol M, et al: Estimates of the cancer incidence and mortality in Europe in 2006. Ann Oncol 18: 581-592, 2007.

2. Steele G Jr and Ravikumar TS: Resection of hepatic metastases from colorectal cancer. Biologic perspective. Ann Surg 210: 127-138, 1989.

3. Ajani JA: Evolving chemotherapy for advanced gastric cancer, Oncologist 10 (suppl 3): 49-58, 2005.

4. Cui Y, Shu XO, Gao Y, et al: Use of complementary and alternative medicine by Chinese women with breast cancer. Breast Cancer Res Treat 85: 263-270, 2004.

5. Miyamoto K, Kishi $\mathrm{N}$ and Koshiura R: Antitumor effect of agrimonin, a tannin of Agrimonia pilosa Ledeb., on transplantable rodent tumors. Jpn J Pharmacol 43: 187-195, 1987.

6. He C, Ji X, Pan Y, et al: Antioxidant activity of alcoholic extract of Agrimonia pilosa Ledeb. Med Chem Res 19: 448-461, 2010.

7. Jung $\mathrm{M}$ and Park M: Acetylcholinesterase inhibition by flavonoids from Agrimonia pilosa. Molecules 12: 2130-2139, 2007.

8. Jung CH, Kim JH, Park S, et al: Inhibitory effect of Agrimonia pilosa Ledeb. on inflammation by suppression of iNOS and ROS production. Immunol Invest 39: 159-170, 2010.

9. Xu X, Qi X, Wang W and Chen G: Separation and determination of flavonoids in Agrimonia pilosa Ledeb. by capillary electrophoresis with electrochemical detection. J Sep Sci 28: 647-652, 2005.

10. Chang HM and But PPH (eds): Pharmacology and Applications of Chinese Materia Medica. World Scientific, Singapore; Philadelphia, PA, USA, 1986. 
11. Chiu LC, Ho TS, Wong EY and Ooi VE: Ethyl acetate extract of Patrinia scabiosaefolia downregulates anti-apoptotic $\mathrm{Bcl}-2 / \mathrm{Bcl}-\mathrm{X}(\mathrm{L})$ expression, and induces apoptosis in human breast carcinoma MCF-7 cells independent of caspase-9 activation. J Ethnopharmacol 105: 263-268, 2006.

12. An L, Tang JT, Liu XM and Gao NN: Review about mechanisms of anti-cancer of Solanum nigrum, Zhongguo Zhong Yao Za Zhi 31: 1225-1226, 1260, 2006 (In Chinese).

13. Tai CJ, Wang CK, Tai CJ,etal: Aqueous extract of Solanumnigrum leaves induces autophagy and enhances cytotoxicity of cisplatin doxorubicin, docetaxel, and 5-fluorouracil in human colorectal carcinoma cells. Evid Based Complement Alternat Med 2013: 514719,2013

14. Yu C, Xu M, Ju W, et al: Active ingredient of enema in treatment of colorectal cancer. Journal of Liaoning University of TCM 16: 50-54, 2014

15. Chou TC and Talalay P: Quantitative analysis of doseeffect relationships: the combined effects of multiple drugs or enzyme inhibitors. Adv Enzyme Regul 22: 27-55, 1984.

16. Livak KJ and Schmittgen TD: Analysis of relative gene expression data using real-time quantitative PCR and the 2(-DeltaDelta C(T)) method. Methods 25: 402-408, 2001.

17. Li J, Sun GZ, Lin HS, et al: The herb medicine formula 'Yang Wei Kang Liu' improves the survival of late stage gastric cancer patients and induces the apoptosis of human gastric cancer cell line through Fas/Fas ligand and $\mathrm{Bax} / \mathrm{Bcl}-2$ pathways. Int Immunopharmacol 8: 1196-1206, 2008.

18. Wagner AD, Grothe W, Haerting J, et al: Chemotherapy in advanced gastric cancer: a systematic review and meta-analysis based on aggregate data, J Clin Oncol 24: 2903-2909, 2006.

19. Matuo R, Sousa FG, Escargueil AE, et al: 5-Fluorouracil and its active metabolite FdUMP cause DNA damage in human SW620 colon adenocarcinoma cell line. J Appl Toxicol 29 308-316, 2009
20. Matsuhashi N, Saio M, Matsuo A, et al: Apoptosis induced by 5 -fluorouracil, cisplatin and paclitaxel are associated with p53 gene status in gastric cancer cell lines. Int J Oncol 26: $1563-1567,2005$

21. Kuramochi H, Tanaka K, Oh D, et al: Thymidylate synthase polymorphisms and mRNA expression are independent chemotherapy predictive markers in esophageal adenocarcinoma patients. Int J Oncol 32: 201-208, 2008.

22. Su F, Overholtzer M, Besser D and Levine AJ: WISP-1 attenuates p53-mediated apoptosis in response to DNA damage through activation of the Akt kinase. Genes Dev 16: 46-57, 2002.

23. Tian C, Zhou ZG, Meng WJ, et al: Overexpression of connective tissue growth factor WISP-1 in Chinese primary rectal cancer patients. World J Gastroenterol 13: 3878-3882, 2007.

24. Lu Z, Zhang R and Diasio RB: Purification and characterization of dihydropyrimidine dehydrogenase from human liver. J Biol Chem 267: 17102-17109, 1992.

25. Diasio RB and Lu Z: Dihydropyrimidine and dehydrogenase activity and fluorouracil chemotherapy. J Clin Oncol 12 2239-2242, 1994.

26. Nita ME, Tominaga O, Nagawa $\mathrm{H}$, et al: Dihydropyrimidine dehydrogenase but not thymidylate synthase expression is associated with resistance to 5-fluorouracil in colorectal cancer. Hepatogastroenterology 45: 2117-2122, 1998.

27. Vande Velde C, Cizeau J, Dubik D, et al: BNIP3 and genetic control of necrosis-like cell death through the mitochondrial permeability transition pore. Mol Cell Biol 20: 5454-5468, 2000. 